\title{
ANALISIS NILAI EKONOMI HUTAN MANGROVE DI DESA MARE KOFO KOTA TIDORE KEPULUAN
}

\author{
Sabaria Niapele*, Muhammad Hi. Hasan* \\ Staf Pengajar Univ. Nuku-Tidore, Email: -
}

\begin{abstract}
ABSTRAK
Penelitian ini bertujuan untuk mengetahui jenis pemanfaatan dan menganalisa nilai ekonomi hutan mangrove di Desa Mare Kofo Kota Tidore Kepulauan. Metode penelitian dengan pengambilan sampel yang dipilih secara sengaja (purfosive) dari masyarakat disekitar hutan mangrove serta yang memiliki akses terhadap hutan mangrove. Nilai Manfaat langsung yang diperoleh masyarakat di sekitar hutan mangrove (local direct use value) didekati dengan laba bersih yang dihasilkan untuk penggunaan lokal. Manfaat tidak langsung didekati dengan metode Replacement cost (metode biaya pengganti). Pendekatan tersebut digunakan untuk mengestimasi nilai manfaat fisik, biologis dan ekoogis sumber daya hutan mangrove dengan kriteria dan standar penilaian. Untuk estimasi nilai manfaat pilihan menggunakan pendekatan benefit transfer. Sementara itu estimasi nilai manfaat keberadaan dengan menggunakan metode Contingent Valuation. Hasil penelitian pemanfaatan langsung hutan mangrove oleh responden di Desa Mare Kofo yaitu: Pemanfaatan kayu bakar, ikan, kerang, cumi dan kepiting. Total nilai ekonomi pemanfaatan hutan mangrove di Desa Mare Kofo yaitu: manfaat langsung sebesar Rp. 34.542.515,59/ha/ tahun, manfaat tidak langsung sebesar $R p$. 153.285.120,17/ha/tahun, manfaat pilihan sebesar Rp. 171.897,38/ha/tahun, dan manfaat keberadaan sebesar Rp. 4.800.000/ha/tahun, sehingga total nilai ekonomi yaitu sebesar: Rp. 192.799.533,1/ha/tahun.
\end{abstract}

Kata Kunci : Nilai, Ekonomi, Hutan, Mangrove

\section{PENDAHULUAN}

1.1. Latar Belakang

Hutan mangrove memiliki peran yang sangat penting bagi kehidupan masyarakat terutama masyarakat yang berada di sekitar hutan mangrove tersebut. Salah satu peranannya yaitu sebagai sumber mata pencaharian bagi masyarakat, karena dapat menghasilkan berbagai produk bernilai ekonomi terutama sebagai penghasil produk kayu, ikan, kerang, kepiting dan lain-lain serta dapat dijadikan sebagai wahana rekreasi dan wisata alam maupun penidikan. Dewasa ini, peranan hutan mangrove bagi lingkungan sekitarnya dirasakan semakin besar, tetapi adanya berbagai dampak merugikan yang dirasakan di berbagai tempat akibat hilangnya hutan mangrove, seperti tsunami,

intrupsi air laut, bahkan kerusakan yang dilakukan oleh manusia sendiri.

Hutan mangrove merupakan salah satu bentuk ekosistem hutan yang unik dan khas serta terdapat pada daerah pasang surut di wilayah pesisir, pantai,dan atau pulau-pulau kecil dan merupakan potensi sumber daya alam yang sangat potensial. Hutan mangrove memiliki nilai ekonomi dan ekologis yang sangat tinggi, tetapi sangat rentan terhadap kerusakan apabila kurang bijaksana dalam mengelola dan melestarikannya.

Secara garis besar, mangrove mempunyai beberapa keterkaian dalam pemenuhan kebutuhan manusia sebagai bahan pangan, papan, dan kesehatan serta lingkungan, dibedakan menjadi lima fungsi yaitu fungsi fisik, fungsi kimia, fungsi biologis, fungsi ekonomi, dan fungsi lain 
(wanawisata). Hamilton dan Snedaker (1994)

dalam Dahuri dkk (2004) mencatat sekitar 58 produk langsung dan tidak langsung yang dapat diperoleh dari mangrove antara lain berupa kayu bakar, bahan bangunan, pupuk, bahan baku kertas, bahan makanan, obatobatan, minuman, peralatan rumah tangga, bahan baku tekstil dan kulit, madu lilin, dan tempat rekreasi.

Pemanfaatan hutan mangrove untuk pemenuhan kebutuhan manusia perlu dimanfaatkan sebaik-baiknya sehingga dapat memberikan manfaat bagi kesejahteraan masyarakat dengan tetap memperhatikan aspek kelestariannya, sehingga manfaat yang diperolehpun dapat tetap lestari dan berkelanjutan. Namun pemanfaatan tersebut terkadang tidak memperhatikan aspek-aspek kelestarian sehingga, menimbulkan kerusakan yang merugikan masyarakat itu sendiri.

Kota Tidore Kepulauan memiliki potensi sumber daya hutan mangrove yang terdapat dibeberapa daerah. Salah satunya hutan mangrove di Desa Mare Kofo yang memiliki luas $\pm 9,62$ Ha. Namun sampai saat ini belum ada kajian ilmiah untuk mengetahui potensi hutan mangrove yang ada di Desa Mare Kofo secara ekonomi. Oleh karena itu dipandang penting untuk melakukan kajian analisis ekonomi untuk mengetahui berapa besar nilai ekonomi hutan mangrove yang terdapat di Kawasan Hutan Mangrove Mare Kofo.

\subsection{Rumusan Masalah}

Berbagai jenis komoditas yang bernilai ekonomi baik berupa hasil hutan, seperti: kayu untuk kayu bakar, bahan bangunan, bahan baku arang, serta komoditas hasil perikanan, seperti: ikan, udang, kepiting, dan kerang-kerangan. Potensi tersebut merupakan asset yang besar untuk pembangunan ekonomi di daerah apabila dikelola secara lestari. Selain itu pemanfaatan dan pengelolaan hutan mangrove dalam menunjang ekonomi masyarakat pesisir menjadi perhatian khusus, oleh karena peran dan fungsi hutan mangrove yang beraneka ragam, seperti sebagai daerah pemijahan, pembesaran dan mencari makan berbagai jenis biota laut, serta fungsi perlindungan dan pengamanan pantai.

Dampak negative akan timbul akibat pemanfaatan hutan mangrove yaitu terjadi kerusakan fisik atau bahkan hilangnya ekosistem mangrove, hal ini akan berdampak pada fungsi ekologis, ekonomi maupu sosial masyarakat. Dampak kerusakan ini akan terus belanjut jika tidak ada solusi untuk mempertahankan keberadaan hutan mangrove tersebut. Oleh karena itu maka dipandang perlu untuk melkukan kajian ekonomi secara mendetail tentang manfaat dan fungsi hutan mangrove dari sisi ekonomi untuk dijadikan landasan dalam pengambilan kebijakan utamanya terkait dengan Pengelolaan Sumber Daya HutanMangrove di Desa Mare Kofo.

\subsection{Tujuan Dan Manfaat Penelitian}

Berdasarkan rumusan masalah tersebut, maka tujuan penelitian adalah untuk :

1. Mengetahui jenis pemanfaatan hutan mangrove di Desa Mare Kofo Kota Tidore Kepulauan

2. Menganalisa nilai ekonomi hutan mangrove di Desa Mare kofo Kota Tidore Kepulauan

Penelitian ini diharapkan memberikan manfaat sebagai berikut:

1. Sebagai bahan informasi ilmiah dalam pengambilan kebijakan pengelolaan dan pemanfaatan hutan mangrove khususnya di Desa Mare Kofo Kota Tidore Kepulauan

2. Sebagai referensi ilmiah bagi peneliti lainnya yang berminat untuk mengkaji bidang yang sama khususnya dalam perencanaan dan pengelolaan sumber daya hutan mangrove di Kota Tidore Kepulauan.

\section{METODE PENELITIAN}

\subsection{Tempat dan Waktu}

Penelitian ini dilaksanakan di Desa Mare Kofo Kota Tidore Kepulauan, selama 6 bulan.

\subsection{Alat dan Bahan}

Alat yang digunakan dalam penelitian ini adalah: Kamera Digital, Recording, alat tulis menulis, kuisoner untuk wawancara dan respondensi. 
บे

2.3. Pengambilan Sampel

Sampel dalam penelitian ini yaitu masyarakat yang memanfaatkan komoditas hutan mangrove secara langsung, yakni pengolah kayu bakar, serta nelayan penangkap ikan, kepiting, serta pengumpul kerang. Pengumpulan data sampel masyarakat pengguna dilakukan secara teknik purposive sampling. Hal ini didasarka pada pertimbangan bahwa sampel merupakan responden yang bersifat spesifik, sehingga penentuan harus dilakukan secara sengaja (purposive).

2.4. Prosedur Penelitian

Respoden dipilih secara sengaja dari masyarakat disekitar hutan mangrove serta yang memiliki akses terhadap hutan mangrove. Wawancara dilakukan dengan masing-masing respoden dengan menggunakan kuisoner untuk memperoleh perkiraan nilai ekonomi yaitu: manfaat langsung, manfaat tidak langsung, manfaat pilihan, dan manfaat keberadaan dari hutan mangrove di Desa Mare Kofo.

\subsection{Variabel penelitian}

Variabel yang akan diukur untuk pengukuran nilai ekonomi atau variable ekonomi meliputu: manfaat langsung (DirectUse Value), Manfaat tidak langsung (Indirect use Value), Manfaat pilihan (Option Value), dan Manfaat Keberadaan (Existence Value).

\subsection{Analisis Data}

Nilai Manfaat langsung yang diperoleh masyarakat di sekitar hutan mangrove (local direct use value) didekati dengan laba bersih yang dihasilkan untuk penggunaan local (Shatirathai, 2003). Manfaat tidak langsung didekati dengan metode Replacement cost (metode biaya pengganti). Pendekatan tersebut digunakan untuk mengestimasi nilai manfaat fisik sumber daya hutan mangrove, manfaat biologis, dan manfaat ekologis dengan kriteria dan standar penilaian sabagaimana yang diajukan oleh Suryono (2006). Untuk estimasi nilai manfaat pilihan menggunakan pendekatan benefit transfer dengan criteria sebagaimana yang diajukan oleh Ruitenbeek
(1991). Sementara itu estimasi nilai manfaat keberadaan dengan menggunakan metode Contingent Valuation.

2.6.1. Jenis Manfaat Langsung

a. Manfaat Langsung kayu bakar adalah nilai ekonomi yang diperoleh dari pengolahan kayu mangrove menjadi kayu bakar, didekati dengan persamaan sebagai berikut:

$\mathrm{NEKb}=\mathrm{QKb} \times \mathrm{PKb} \times \mathrm{RTKb}-\mathrm{CKb}$, Dimana diketahui $\mathrm{NEKb}$ merupakan nilai ekonomi kayu bakar (Rp/tahun), PKb merupakan nilai jumlah volume kayu bakar ( $\mathrm{m}^{3} /$ tahun), PKb merupakan harga kayu bakar $\left(R p / m^{3}\right)$, RTKb merupakan jumlah rumah tangga pengolahan kayu bakar (kk), CBk merupakan biaya pengolahan kayu bakar (Rp/tahun)

b. Manfaat langsung penagkapan ikan/udang adalah nilai ekonomiyang diperoleh dari penagkapan ikan/udang didekati dengan persamaan berikut:

NEPi = QPi x PPi x RTPi - CPi. Dimana diketahui NEPi merupakan nilai ekonomi penangkapan ikan/udang ( $R p /$ tahun), QPi merupakan Jumlah ikan/udang hasil tangkapan (kg), RTPi merupakan jumlah nelayan penangkapan ikan/udang (orang), dan CPi merupakan biaya penangkapan ikan/udang (RP/tahun)

c. Manfaat langsung penangkapan kepiting adalah nilai ekonomi yang diperoleh dari penangkapan kepiting, didekati dengan persamaan berikut:

NEPk = QPk $\times$ PPk $\times$ RTPk - CPk. Dimana NEPk merupakan nilai ekonomi penangkapan kepiting (RP/tahun), QPk merupakan jumlah kepiting hasil tangkapan (kg), PPk merupakan harga jual kepiting hasil tangkapan (Rp/Kg), RTPk merupakan jumlah nelayan penangkap kepiting (orang), dan CPk merupakan biaya operasional pengkapan kepiting (Rp/tahun)

d. Manfaat langsung pengumpulan kerang adalah nilai ekonomi yang diperoleh dari penangkapan kerang, didekati dengan persamaan sebagai berikut:

NEPkr = QPkr x PPkr x RTPkr - CPkr, Dimana diketahui NEPkr merupakan nilai 
ekonomi pengumpulan kerang (Rp/tahun), QPkr merupakan jumlah kerang hasil pengumpulan $(\mathrm{Kg})$, PPkr merupakan harga jual kerang hasil pengumpulan $(\mathrm{Rp} / \mathrm{Kg})$, RTPkr merupakan jumlah nelayan pengumpulan kerang (orang), dan CPkr merupakan biaya operasional pengumpulan kerang (Rp/tahun).

\subsubsection{Nilau Ekonomi Hutan mangrove}

\section{a. Manfaat Langsung}

Manfaat langsung atau Direct Use Value adalah merupakan jenis manfaat yang langsung dapat diperoleh dari hutan mangrove atau sebagai bentuk manfaat aktual yang dilakukan oleh masyarakat, seperti mengolah kayu bakar, mengkap ikan, menangkap kepiting, menangkap udang, mengumpulkan kerang dan lainlain, dihitung menggunakan rumus sebagai berikut: $\mathrm{TML}=\mathrm{ML}_{1}+\mathrm{ML}_{2}+\mathrm{ML}_{3}+\mathrm{ML}_{4}+$ n, Dimana diketahui bahwa TML merupakan nilai manfaat langsung kayu bakar, ML2 merupakan nilai manfaat langsung penangkapan ikan, $\mathrm{ML}_{3}$ merupakan nilai manfaat langsung penangkapan kepiting, dan ML4 merupakan nilai manfaat langsung pengumpulan kerang. Sementara $\mathbf{n}$ merupakan jenis manfaat langsung lainnya.

\section{b. Manfaat Tidak Langsung}

Perhitungan manfaat tidak langsung hutan mangrove digunakan digunakan metode replacement cost. Manfaat tidak langsung dari hutan mangrove diperoleh dari suatu ekosistem secara tidak langsung, yakni berupa manfaat fisik, biologis, dan ekologis (Suryono, 2006). Manfaat tidak langsung fisik yakni sebagai abrasi pantai (Fahrudin, 1996) dalm Abdul dan Rohmady (2014) dinilai dari adanya pembuatan bangunan air yaitu yaitu pemecah gelombang ombak (Suryono, 2006), manfaat tidak langsung biologis yakni sebagai penyedia bahanbahan organik bagi biota yang hidup di dalam kawasan hutan mangrove (Adrianto dkk, 2004) maupun sebagai tempat pemijahan dan asuhan (Suryono, 2006) dan manfaat tidak langsung ekologis yakni diestimasi dari adanya serapan karbon. Formula yang digunakan untuk menghitung nilai manfaat tidak langsung yang dihitung sesuai dengan nilai rupiah adalah:

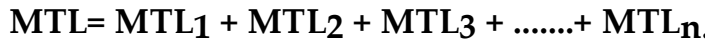

Dimana diketahui MTL merupakan manfaat tidak langsung, MTL1 merupakan manfaat tidak langsung peredam gelombang, MTL2 Manfaat tidak langsung sebagai penyedia bahan organic, dan $\mathrm{MTL}_{3}$ merupakan manfaat tidak langsung sebagai penyedia karbon.

d. Manfaat pilihan

Nilai manfaat pilihan didekati dengan mengacu pada nilai keanekaragaman hayati (biodiversity) hutan mangrove di Indonesia, yakni sebesar USD 1.500 per $\mathrm{km}^{2}$ per tahun atau sebesar USD 15 per ha per tahun (Ruitebeek, 1992). Untuk mengetahui manfaat pilihan dari hutan mangrove, digunakan pendekatan dengan formula sebagai berikut:

$\mathrm{MP}=\mathrm{MPb}=($ USD 15 per ha) $\mathrm{x}$ Luas lahan mangrove. Dimana diketahui MP merupakan manfaat pilihan. Perhitungan nilai manfaat pilihan tersebut dilakukan dengan mengkorvesikan nilai keanekaragaman hayati USD 15 per ha tersebut ke dalam nilai rupiah

e. Manfaat Keberadaan

Manfaat keberadaan atau lebih dikenal dengan istilah manfaat eksistensi merupakan jenis manfaat yang dirasakan oleh masyarakat dari keberadaan ekosistem hutan mangrove dari manfaat lainnya, yakni manfaat langsung, manfaat tidak langsung, dan manfaat pilihan. Manfaat keberadaan merupakan nilai ekonomi keberadaan secara fisik dari ekosistem hutan mangrove. Metode yng digunakan untuk menghitung besarnya nilai ekonomi melalui pendekatan Contingent Valuation Method atau lebih dikenal dengan CVM

f. Kuantifikasi Seluruh Manfaat dan Fungsi Hutan Mangrove.

Setelah seluruh komuditas dari hutan mangrove dapat diidentifikasi, selanjutnya adalah mengkuantifikasi seluruh komoditas kedalam nilai rupiah. Teknik kuantifikasi yang digunakan adalah: 1). Nilai pasar local, 2). Harga tidak langsung, 3). Contingent valuation method (CVM), 4). 
Nilai Ekonomi Total (NET)/Total Economic Value (TEV), merupakan penjumlahan dari nilai pemanfaatan dan nilai bukan pemanfaatan hutan mangrove yang telah diidentifikasi dan dikuantifikasikan. Untuk mengetahui nilai ekonomi total (NET/TEV) adalah sebagai berikut: NET = ML + MTL + MP +ME. Dimana diketahui NET merupakan nilai ekonomi total, ML merupakan nilai manfaat langsung, MTL merupakan nilai manfaat tidak langsung, MP merupakan nilai manfaat pilihan, dan ME merupakan nilai manfaat eksistensi.

\section{HASIL PENELITIAN}

3.1. Letak Dan Luas Wilayah

Luas wilayah Kecamatatan Tidore Selatan 42,40 $\mathrm{Km}^{2}$ dengan letak antara: 00-10 lintang Utara (LU) dengan Batas Wilayah Yaitu :

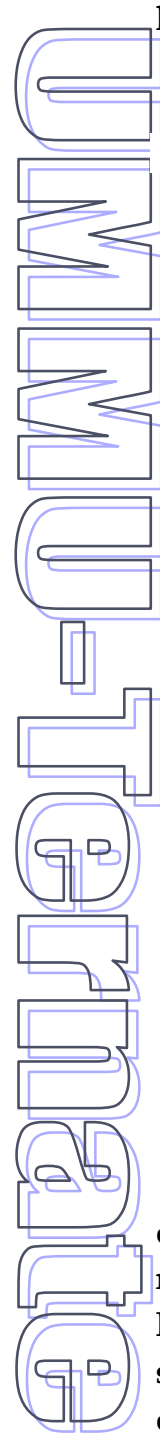

\begin{tabular}{cccc}
\multicolumn{4}{c}{ Kota Tidore Kepulauan Berdasarkan Umur. } \\
\hline No & $\begin{array}{c}\text { Umur Responden } \\
\text { (Tahun) }\end{array}$ & $\begin{array}{c}\text { Jumlah } \\
\text { Responden }\end{array}$ & Persentase (\%) \\
\hline 1. & $15-24$ & - & - \\
2. & $25-34$ & 8 & 40 \\
3. & $35-44$ & 7 & 35 \\
4. & $45-54$ & 3 & 15 \\
5. & $55-64$ & 2 & 10 \\
\hline
\end{tabular}

Sumber : Data Primer Setelah Diolah (2017)

Tabel 2. Responden Yang Memanfaatkan mangrove Di Desa Mare Kofo Kota Tidore Kepulauan baerdasarkan tingkat pendidikan.

\begin{tabular}{cccc}
\hline No & Tingkat pendidikan & Jumlah Responden & Persentase (\%) \\
\hline 1. & Tidak Bersekolah & - & - \\
2. & SD & 17 & 85 \\
3. & SMP & 2 & 10 \\
4. & SMA & 1 & 5 \\
5. & Perguruan Tinggi & - & - \\
\hline
\end{tabular}

Sumber: Data Primer Setelah Diolah (2017)

Berdasarkan tabel 2 dijelaskan bahwa dari 20 responden yang memanfaatkan mangrove di Desa Mare Kofo Kota Tidore Kepulauan dilihat dari tingkat pendidikannya sangat berfariasi mulai dari tingkat SD sampai dengan SMA. Tingkat pendidikan responden yang tertinggi yaitu SD sebanyak 85\%, sedangkan yang terendah yaitu SMA sebanyak
1. Sebelah Utara Berbatasan Dengan Hutan Lindung

2. Sebelah Selatan Berbatasan Dengan Pulau Moti

3. Sebelah Barat Berbatasan Dengan Kelurahan Toloa Kecamatan Tidore Utara

4. Sebelah Timur Berbatasan Kelurahan Seli Kecamatan Tidore.

3.2. Karakteristik Responden.

\subsubsection{Usia Responden}

Berdasarkan data dilapangan diketahui usia responden dapat dilihat pada Tabel 1 . Tabel 1 menunjukan bahwa masyarakat yang memanfaatkan mangrove di Desa Mare Kofo tergolong dalam usia produktif yaitu sebanyak $90 \%$.

\subsubsection{Tingkat Pendidikan Responden}

Berdasarkan data lapangan tingkat pendidikan responden di Desa Mare Kofo dapat dilihat pada Tabel 2.

Tabel 1. Responden yang Memanfaatkan Mangrove Di Desa Mare Kofo Kecamatan Tidore Selatan 
Berdasarkan hasil penelitian di lapangan hasil menunjukan bahwa jenis -jenis pemanfaatan mangrove di Desa Mare Kota Tidore Kepulauan dapat dilihat pada Tabel 3. Berdasarkan tabel 6 di atas menunjukan bahwa pemanfaatan kayu bakar sebanyak 140,16 $\mathrm{m}^{3}$ per tahun. Kayu bakar yang dimanfaatkan oleh responden yaitu ranting kayu yang telah kering. Sedangkan pemanfaatan biota laut yang paling tertinggi yaitu pemanfaatan ikan sebanyak $319,2 \mathrm{~kg} / \mathrm{tahun}$. Hal ini disebabkan karena semua responden memnfaatkan ikan untuk dikonsumsi setiap harinya. Sedangkan pemanfaatan yang terendah yaitu adalah cumi sebanyak $122 \mathrm{~kg} /$ tahun. Meskipun responden yang memanfaatkan cumi lebih banyak dibandingkan dengan responden yang memanfaatkan kepiting tetapi tingkat konsumsi kepiting oleh responden lebih banyak dibandingkan tingkat konsumsi cumi. Hal ini yang menyebabkan sehingga tingkat pemanfaatan cumi lebih rendah bila di bandingkan dengan pemanfaatan lainnya.

3.4. Nilai Ekonomi Total Manfaat Langsung Hutan Mangrove di Desa Mare Kofo Kecamatan Tidore Selatan Kota Tidore Kepulauan.

Berdasarkan hasil analisis data di lapangan diketahui nilai ekenomi total pemanfaatan langsung hutan mangrove di Desa Mare Kofo Kecamatan Tidore Selatan Kota Tidore Kepulauan dapat dilihat pada tabel 4.

Tabel 3. Pemanfaatan Langsung Hutan Mangrove per tahun di Desa Mare Kofo Kecamatan Tidore Selatan Kota Tidore Kepulauan.

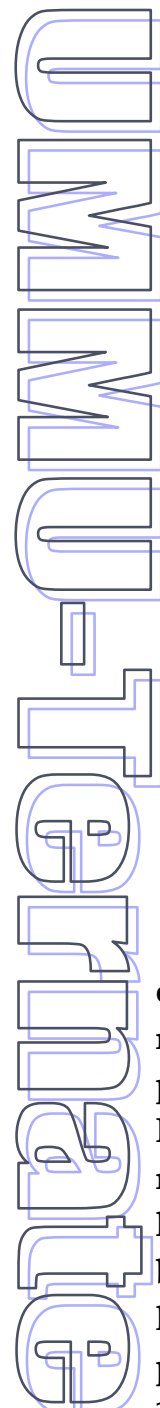

\begin{tabular}{ccc}
\hline No & Pemanfaatan & Pemanfaatan per tahun \\
\hline 1. & Kayu Bakar & $140,16 \mathrm{~m}^{3}$ \\
2. & Ikan & $319,2 \mathrm{Kg}$ \\
3. & Kerang-kerangan & $182,4 \mathrm{Kg}$ \\
4. & Kepiting & $144 \mathrm{Kg}$ \\
5. & cumi & $122 \mathrm{Kg}$ \\
\hline
\end{tabular}

Sumber: Data Primer Setelah Diolah (2017)

Table 4. Nilai Ekonomi Manfaat Langsung Hutan Mangrove di Desa Mare Kofo.

\begin{tabular}{cccc}
\hline No & Pemanfaatan & $\begin{array}{c}\text { Nilai Ekonomi Total } \\
(\mathrm{RP} / \mathrm{Thn})\end{array}$ & $\begin{array}{c}\text { Nilai Ekonomi Rata-Rata } \\
(\mathrm{Rp} / \mathrm{Ha} / \mathrm{Thn})\end{array}$ \\
\hline 1. & Kayu Bakar & 105.120 .000 & 10.950 .000 \\
1. & Ikan & 127.630 .000 & $13.267 .151,77$ \\
2. & Kerang & 45.500 .000 & $4.729 .729,72$ \\
3. & Kepiting & 17.280 .000 & $1.796 .257,80$ \\
4. & Cumi & 36.550 .000 & $3.799 .376,30$ \\
\hline Total & & 332.080 .000 & $34.542 .515,59$ \\
\hline Sumber: Data Primer Setelah Diolah (2017)
\end{tabular}

Tabel di atas menunjukan bahwa nilai ekonomi tertinggi manfaat langsung hutan mangrove di Desa Mare Kofo yaitu pemanfaatan ikan sebesar Rp 127.630.000/tahun. Hal ini disebabkan karena semua responden memanfaatkan ikan setiap harinya dan tingkat konsumsi ikan/hari oleh responden lebih banyak dibandingkan dengan pemanfaatan lainnya. Berdasarkan data yang diperoleh nilai pemanfaatan cumi lebih rendah yaitu sebanyak $122 \mathrm{~kg}$ bila dibandingkan dengan pemanfaatan kepiting yaitu sebesar $144 \mathrm{~kg}$ tetapi nilai ekonomi terendah yaitu pemanfaatan kepiting sebesar Rp 17.280.000/tahun. Hal ini disebabkan karena faktor harga dimana harga cumi lebih mahal bila dibandingkan dengan harga kepiting sehingga nilai ekonomi cumi lebih tinggi yaitu sebesar $R p$ 36.550.000/tahun. Untuk lebih jelasnya dapat dilihat diagram prosentase nilai ekonomi total manfaat langsung hutan mangrove di Desa Mare Kofo Kota Tidore Kepulauan. 


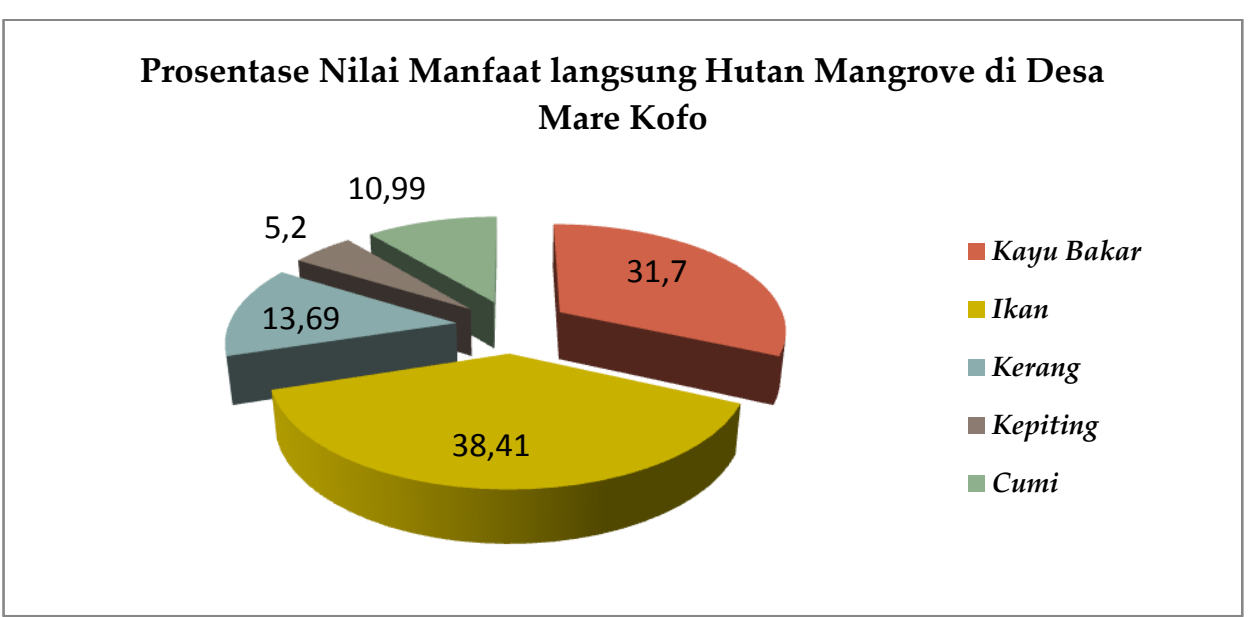

Gambar 1. Diagram Prosentase Pemanfaatan langsung Hutan Mangrove di Desa Mare Kofo

Berdasarkan digram diatas menunjukan bahwa nilai total ekonomi tertinggi yaitu pemnfaatan ikan sebesar $38,41 \%$, sedangkan nilai ekonomi total yang terendah yaitu pemanfaatan kepiting sebesar $7,61 \%$.

3.5. Manfaat Tidak Langsung Mangrove di Desa Mare Kofo.

Berdasarkan data dilapangan diketahui bahwa manfaat tidak langsung hutan mangrove di Desa Mare Kofo terdiri dari penahan abrasi, penjaga kestabilan rantai makanan, penyerap karbon. Untuk lebih jelasnya dapat dilihat nilai ekonomi manfaat tidak langsung pada Tabel 5.

\subsection{Manfaat Pilihan}

Manfaat pilihan didekati dengan manfaat keanekaragaman hayati (biodiversity). Menurut (Suryono, 2006; Apung 2011 dalam Abdul Rakhfid dan Rochmady 2013). Manfaat pilihan merupakan jenis pemanfaatan yang mencerminkan nilai keanekaragaman hayati (biodiversity). yang dapat ditangkap dari keberadaan hutan mangrove. Ruitenbeek (1992) mengatakan bahwa nilai keanekaragaman hayati (biodiversity). hutan mangrove di Indonesia khususnya di Teluk Bintani, Irian Jaya Papua adalah sebesar USS 1500 per hektar per $\mathbf{k m}^{2}$ per tahun atau USS 15 per hektar per tahun.

Nilai manfaat pilihan hutan mangrove Desa Mare Kofo (luas 9,62 ha ) sebesar Rp. 2.062.768,5 per tahun atau sebesar Rp. 171.897,38 per hektar per tahun ( asumsi nilai kusr Bank Indonesia 20171 USS = 14295).

\subsection{Manfaat Keberadaan}

Manfaat keberadaan hutan mangrove Desa Mare Kofo diperoleh dengan teknik valuasi yang didasarkan atas survey untuk mengetahui keinginan membayar atau WTP (Willingnes to pay). Berdasarkan hasil wawancara di Desa Mare Kofo Kecamatan Tidore Selatan ditabulasi untuk mendapatkan nilai WTP, nilai manfaat keberadaan hutan mangrove di Desa Mare Kofo dapat dilihat pada Tabel 6.

Table 5. Nilai ekonomi manfaat tidak langsung hutan mangrove di Desa Mare Kofo.

\begin{tabular}{llrrr}
\hline No & Jenis Manfaat & $\begin{array}{l}\text { Nilai } \\
\text { (Rp/Thn) }\end{array}$ & Manfaat & \multicolumn{1}{c}{$\begin{array}{l}\text { Nilai manfaat } \\
\text { (Rp/ha/thn) }\end{array}$} \\
\hline 1. & Penahan abrasi & 673.400 .000 & 70.000 .000 \\
2. & Penjaga kestabilan rantai makanan & 1.793 .649 & 186.450 \\
3. & Penyerap karbon & $799.409 .207,03$ & $83.098 .670,17$ \\
\hline \multicolumn{2}{c}{ Total } & $1.474 .602 .856,03$ & $153.285 .120,17$ \\
\hline
\end{tabular}

Sumber: Data Primer Setelah Diolah ( 2017) 
Tabel 6. Nilai Manfaat Keberadaan Hutan Mangrove di Desa Mare Kofo Kecamatan Tidore Selatan Kota Tidore.

\begin{tabular}{lc}
\hline Indicator Penelitian & Desa Mare Kofo \\
& \\
\hline Responden & 20 \\
Luas Hutan(ha) & 9,62 \\
Total Nilai WTP/ha/tahun & 4.800 .000 \\
Nilai Manfaat(Rp/tahun) & 46.176 .000
\end{tabular}

Sumber: Data Primer Setelah Diolah 2017

Berdasarkan tabel diatas nilai rata-rata manfaat keberadaan hutan mangrove di Desa Mare Kofo sebesar Rp.4.800.000 per hektar per tahun . Sehingga nilai manfaat Keberadaan hutan mangrove di Desa Mare Kofo sebesar Rp. 46.176.000 per tahun.

\subsection{Nilai Ekonomi Total Hutan Mangrove}

Berdasarkan hasil identifikasi dan kuantifikasi seluruh manfaat, maka nilai ekonomi total hutan mangrove di Desa Mare Kofo Kecamatan Tidore Selatan daapat dilihat pada Table 7.
Berdasarkan tabel di atas menunjukan bahwa manfaat tertinggi nilai ekonomi yaitu manfaat tidak langsung sebesar Rp 1.474.602.856,03/tahun. Sedangkan manfaat terendah yaitu manfaat pilihan sebesar 171.897,38/tahun dengan jumlah total nilai ekonomi sebesar $R p$ 192.799.533,1/ha/tahun. Untuk lebih jelasnya dapat dilihat pada diagram prosentase nilai ekonomi total hutan mangrove di Desa Mare Kofo pada diagram pada Gambar 2.

Table 7. Nilai Total Ekonomi Manfaat Hutan Mangrove di Desa Mare Kofo Kecamatan Tidore Sealatan tahun 2017.

\begin{tabular}{lccc}
\hline No & jenis manfaat & Rp/ha/thn & Rp/thn \\
\hline 1. & manfaat langsung & $34.542 .515,59$ & 332.080 .000 \\
2. & manfaat tidak langsung & $153.285 .120,17$ & $1.474 .602 .856,03$ \\
3. & manfaat pilihan & $171.897,38$ & $2.062 .768,50$ \\
4. & manfaat keberadaan & 4.800 .000 & 46.176 .000 \\
\hline & Total & $192.799 .533,1$ & 1.854 .921 .624 \\
\hline
\end{tabular}

Sumber: Data Primer Setelah Diolah ( 2017)

Prosentase Nilai Ekonomi Total Hutan Mangrove di Desa Mare Kofo

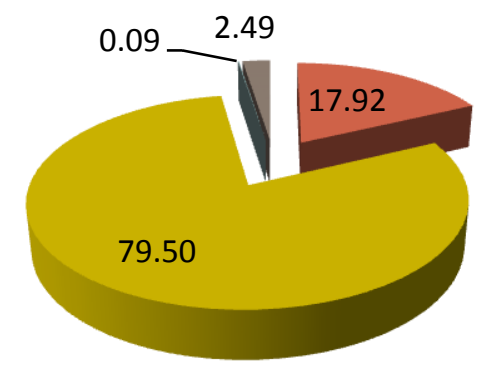

$$
\begin{aligned}
& \text { manfaat langsung } \\
& \text { manfaat tidak langsung } \\
& \text { manfaat pilihan } \\
& \text { manfaat keberadaan }
\end{aligned}
$$

Gambar 2. Diagram proporsi nilai ekonomi total hutan mangrove di Desa Mare Kofo Kecamamtan Tidore Selatan. 


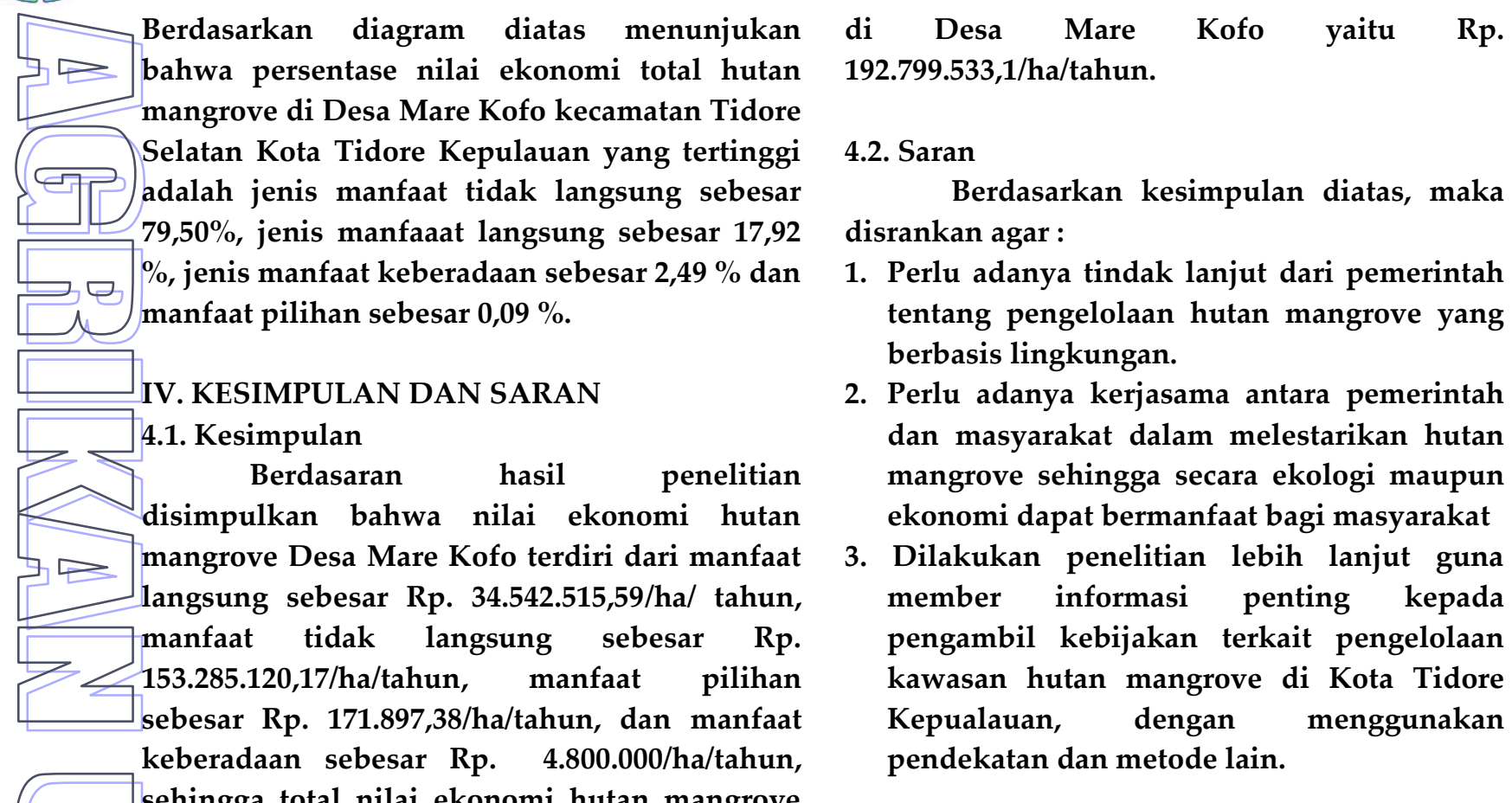

\section{DAFTAR PUSTAKA}

AdriantoI., Mujio., dan Whyudin., 2004, Model Pengenalan Konsep dan Metodologi Valuasi Ekonomi Sumberdaya Pesisi dan Laut Pusat Kajian Sumberdaya Pesisir dan Laut Institusi Pertanian Bogor (PKSPL). Bogor

Hairiah dan Rahayu, 2007. Pengukuran Karbon Tersimpan di Berbagai Macam Penggunaan Lahan. Word agroforestry Centre. ICRAF Southeast Asia Regional Office. Bogsxor

Harahab, N. 2010. Penilaian Ekonomi Ekosistem Hutan Mangrove dan Aplikasinya Dalam Perencanaan Wilayah Pesisir. Graha Ilmu , Yogyakarta

Lewenussa, I. 2011. Analisis Titik Impas Dan Waktu Pengembalian Investasi Usaha Purse Seine Di Dusun Kilwouw. Laporan PKL. Fakultas Perikanan Dan Ilmu Kelautan Universitas Pattimura. Ambon

Mac Nae, W. 1968. A General Account Of Fauna And Flora Of Mangrove Swamps And Forest In Indowest-Fasific Regional. Dalam: Adv Mar. Biol. 6:73-270

McLeod and Salm, 2006. Managing Mangroves for Resilience to Climate Change. IUCN, Gland, Switzerland. 64 pp (download dari www.nwture.org/marine)

Munangsihe.,1993. Enviromental Economics and Sustainable Development. Word Bank Enviromental Paper Number 2

Pearce, D. dan Marlon.,1994. The Economic Value Of Biodeversity. IUNC. Earthscan Publication, London

Rakhid, A dan Rohmady., 2014 Analisis Nilai Ekonomi Hutan Mangrove di Kabupaten Muna (Studi Kasus di Desa Labone Kecamatan Lasalepa dan desa Wabitining Kecamatan Lohia). Jurnal Ilmiah Agribisnis dan Perikanan Universitas Muhamadiah Maluku Utara. Vol.6 Edisi Khusus Januari 2014. ISSN 1979-6071. hal. 82-102

Ruitenbeek, H. J., 1992. Mangrove Management : An Economic Analysis of Management Option with a Focus on Bituni Bay, Irian Jaya. Environmental management Development in Indonesia Project. (EMDI), Jakarta.

Sathiratthai, 2003., Ekonomic Valuation Of Mangroves And The Roles Of Local Communities In The Conservation Of Natural Resources: Case Stady Of Surat Thani, Sout Of Thailand, Economy And Environment Program For Southeast Asia Research Reports. 
Sihite.et al, 2005, Masyarakat dan Cagar Alam Teluk Bentuni Antara Fakta dan Harapan. The Nature Conservancy (TNC), Southeast Asia Center for Marine Protected Areas (SEA CMPA). Penerbit. Sanur Bali Indonesia

Steenis, C.G.G.J. 1978. Flora. Pradnya Paramita, Jakarta

Suryono, T., 2006. Penilaian Ekonomi Lingkungan Terhadap Konversi Hutan Mangrove Menjadi Tambak dan Pemukiman (Studi Kasus Di Hutan Angke Kapuk Jakarta Utara). Tesis. Sekolah Pascasarjana. Institut Pertanian Bogor. Bogor.

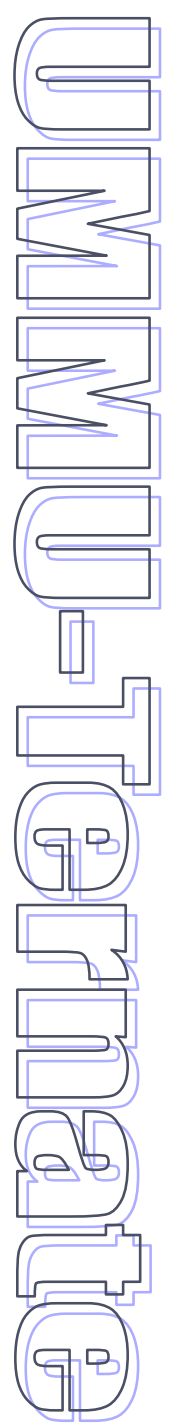

